\title{
Health Vulnerabilities among Migrant/Mobile Populations in Urban Settings of East and Southern Africa: A Regional Synthesis of Evidence from Literature.
}

\author{
Namuunda Mutombo ${ }^{1}$, Blessing Mberu ${ }^{1}$, Donatien Beguy ${ }^{1}$, Kanyiva Muindi ${ }^{1}$, Mike Mutua ${ }^{1}$, \\ Cheikh Faye ${ }^{1}$, Nkechi Obisie-Nmehielle ${ }^{2}$ Erick Ventura ${ }^{2}$. \\ ${ }^{1}$ Population Dynamics and Reproductive Health, African Population and Health Research Centre, \\ Nairobi Kenya \\ ${ }^{2}$ International Organization on Migration, Pretoria South Africa. \\ nmutombo@aphrc.org
}

\begin{abstract}
Using the principles of reputational case selection sampling procedure and thematic search of electronic databases and websites, we implemented a regional synthesis of evidence on the health vulnerabilities of migrant and mobile populations in urban areas of East and Southern Africa. The review identified key health challenges relating to various diseases, including the increasing challenge of non-communicable diseases, such as diabetes among migrants by 2030 . While figures are difficult to obtain, our review suggested high levels of urban migrants, including refugees, internally displaced persons (IDPs) and asylum seekers in urban areas of the region, which for undocumented migrants poses particular logistics challenges in terms of administering targeted interventions, more so in contexts where poor socioeconomic situations of countries do not provide them with opportunities to become self-reliant and less dependent on humanitarian assistance. This calls for policies, program interventions and research investments targeting vulnerable migrant and mobile groups in the region.
\end{abstract}

Key Words: Migrant/Mobile populations; health vulnerabilities; health services, ESA region; sub-Saharan Africa

\section{Résumé}

En utilisant les principes de procédures d'échantillonnage de sélection des cas de réputation et recherche thématique des bases de données électroniques et de sites web, nous avons mis en œuvre une synthèse régionale de données sur les vulnérabilités de la santé des populations migrantes et mobiles dans les zones urbaines de l'Afrique orientale et australe. L'examen a identifié les principaux défis de santé liés à diverses maladies, y compris le défi croissant de maladies non transmissibles, telles le diabète chez les migrants d'ici 2030. Alors que les chiffres sont difficiles à obtenir, notre examen a suggéré des niveaux élevés de réfugiés urbains, les personnes déplacées à l'intérieur (PDI) et les demandeurs d'asile dans les zones urbaines de la région, ce qui pose notamment des problèmes de logistique en termes d'administration des interventions ciblées, plus dans des contextes où pauvres situations socio-économiques des pays ne leur offrent pas la possibilité de devenir autonomes et moins dépendants de l'aide humanitaire. Cela exige des politiques, les interventions des programmes et des investissements de recherche ciblant les migrants vulnérables et des groupes mobiles dans la région.

\section{Introduction}

The East and Southern Africa region has a long history of migratory movements dating back to the pre-colonial era (Crush et al., 2005). The pre-colonial movements were associated with the settling of different ethnic groups and the rural economies that involved hunting, gathering and shifting cultivation. At the start of the colonial period, the recorded increased levels of mobility was linked to the development of economic centers or urban areas with economic opportunities that encouraged ruralurban migration. In the post-colonial period, these movements have continued largely also for economic reasons. As Hunt (1989) observed, the pattern of industrial development in Southern, East and Central Africa, which was followed by colonization was based on a migrant labor system. The other reason is the 
search for asylum due to civil wars or political instability, which have ravaged some parts of the region for decades. Consequently, different dimensions of internal and international mobility and migration, have been a permanent feature of countries in the region. The International Organization for Migration (IOM) has identified 12 types of migrants in the region namely: migrant/mobile workers; regular migrants/documented migrants; irregular migrants/undocumented migrants; asylum seekers; refugees; internally displaced migrants; economic migrants; trafficked persons; seasonal migrant workers; cross-border traders; labor migrants; and internal migrants (Veary and Bleeker-Jurgens, 2010).

Several studies have documented the implications of these different dimensions of movements for health and other outcomes for migrants/mobile populations as well as the host communities. Cities are attractive to many people around the world because they offer better choices (such as good quality housing), opportunities (such as employment) and services (such as education and health care). This often explains most of rural-urban migration. Consequently, more and more people live in cities around the world, with 54 per cent of the world's population residing in urban areas in 2014 (United Nations, 2014). For Africa, recent report showed that $40 \%$ of African population currently live in urban areas but the population of urban residents is projected to increase to $56 \%$ by 2050 (United Nations, 20/4). However, cities also concentrate risks and hazards for health, which is exacerbated by the inability of countries to provide basic social and economic infrastructure and opportunities for a large segment of urban residents. While 80 percent of the urban population will be living in less developed countries by the year 2030 (Cohen, 2006), the urban sector's share of the poor is also on the rise and several rural pathogens have adapted to urban environments (Alirol et al., 20I I). In fact, social and economic changes due to urbanization have been implicated among drivers of increasing noncommunicable diseases in low and middle income countries (Leon 2008). A corpus of studies have shown increasing urbanization of poverty, with a significant proportion of urban population living in slums or slum-like conditions, characterized by limited access to water and sanitation, poor housing conditions, limited employment opportunities and the near absence of the public sector services (African Population and Health Research Center [APHRC], 2002; 20I4). This pattern of urban growth has been linked to appreciable deterioration of key urban health and social indicators, resulting into high rates of unwanted pregnancies, high fertility levels, STIs, and poor maternal and child health outcomes (Garenne, 2006; UN-Habitat, 2008; UN-Habitat and WHO, 20I0; Zulu et al., 2002). Countries of East and Southern Africa are heavily burdened with HIV, as well as other communicable diseases such as tuberculosis. Substantive literature for individual countries and localities has recognized the specific vulnerability of migrants to communicable diseases, especially the specific role of migration for HIV/AIDS infection and control (Brockerhoff \& Biddlecom, 1999; Lurie, 2004; Mazars et al., 2013). A range of different research activities by the International Organization on Migration have documented how the migration process and the social determinants of health interact to affect the health of migrants within the east and southern Africa context (IOM, 2009). Figure I summarizes in a framework the theoretical interactions of the factors affecting the well-being of migrants during the migration process. 
Figure I Framework on the factors affecting the well-being of migrants during the migration process

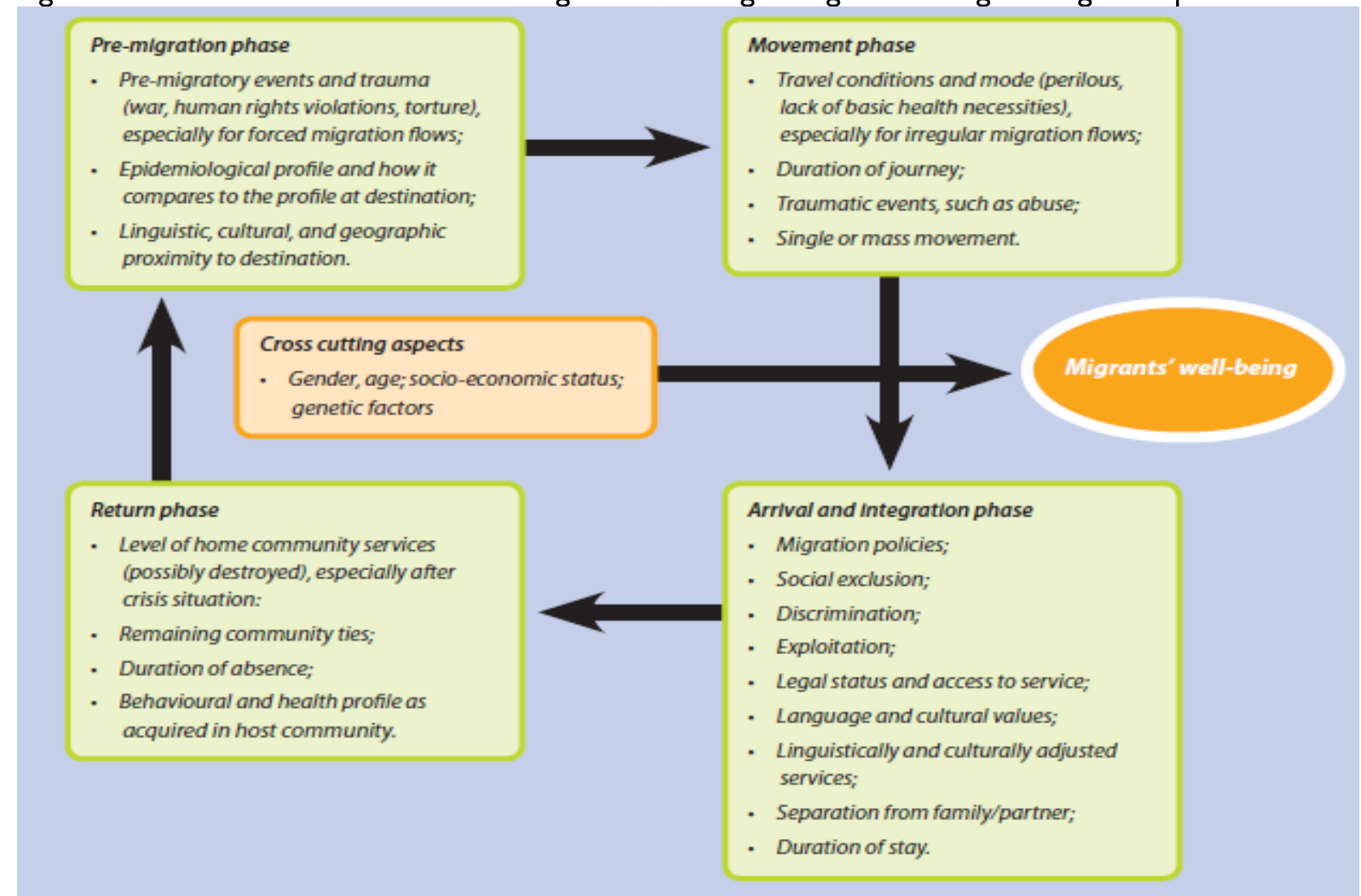

Source: IOM 2009.

However, a region-wide perspective and data on migration and health are scanty and no systematic review of literature has been undertaken on the health vulnerabilities faced by urban migrants in the region. This is in spite of the body of knowledge generated at individual country level and localities, as well as the contiguous nature of countries in East and Southern Africa, which is expressed through political and economic groupings as Common Market for Eastern and Southern Africa (COMESA), Southern African Development Community (SADC) and East African Community (EAC). While the bulk of studies on migration and health in sub-Saharan Africa had focused on countries of Eastern and Southern Africa, the so called "AIDS Belt" (Brockerhoff \& Biddlecom, 1999; French \& Dishion, 2003; Kaufman et al. 2002), most of the studies undertaken are constrained by limited coverage and a regional perspective remain limited in both research, policy and program agendas. Distress migration engendered by civil wars, recurring droughts, famine, political conflicts and transitions, as well as unfavorable government policies and poor governance across countries in the region and consequent health outcomes has implications for the entire region (Adepoju, 1977; Carballo, 2005; Mberu, 2006). A comprehensive region-wide understanding of migration process and systems, together with the relationships between internal and international migration and health vulnerabilities remain a critical research gap that needs to be addressed. This paper, is an important step in providing a coherent evidence on health vulnerabilities faced by migrant and mobile populations and host communities in the urban settings of East and Southern Africa (ESA).

\section{Data and Methods}

We utilize both published and unpublished literature based on previous work done by IOM, APHRC and other researchers in the area of migration and health in urban settings of the ESA region. In conducting the desk review, we drew on the sampling techniques of qualitative inquiry, particularly on the principles of reputational case selection sampling procedures, in which instances are chosen on the recommendation of an expert or key informant (Miles \& Huberman, 1994). Consequently, we used the expertise within the team of researchers at the African Population and Health Research Center (APHRC) and the International Organization on Migration to identify relevant literature that would be useful to be included in the study. Our review of the literature on the list of recommended readings led us to employ additional strategies for locating other relevant documents, including searching electronic databases and websites. Specific sites, particularly IOM online publications were targeted for articles and other documents relevant to migration and health in the 
region of interest. Electronic articles were searched through Google scholar along thematic areas relevant to the review. The key words that guided the search included migration and mobile populations, subSaharan Africa, East and Southern Africa, health vulnerabilities and health services. A total of 72 documents were reviewed, with peer reviewed articles being the majority, followed by technical reports and "other" forms of documents including books/book chapters and monographs (Figure 2):

Figure 2: Percent distribution of documents used in the literature by type; $n=72$.

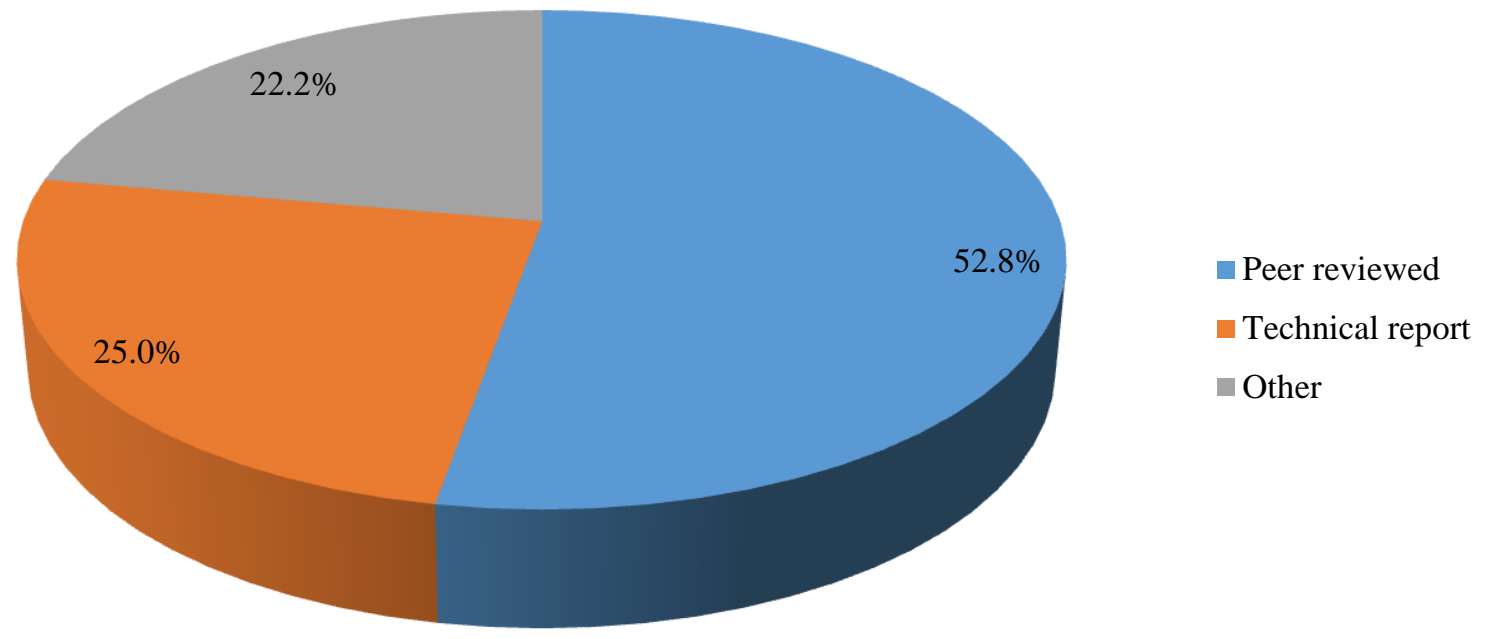

\section{Key Findings}

\section{An overview of health vulnerabilities}

Health vulnerability is the degree to which a population, individual or organization is unable to anticipate, cope with, resist and recover from the impacts of diseases or epidemics (Wisner and Adams, 2002:5). Generally we find that migrants in East and Southern Africa region face different health vulnerabilities throughout the migratory period, starting from the onset of migration as soon as they leave their origin community or country, through the transit period for most international migrants, until their destinations. Most migrants rarely have health insurance to access necessary health care while in transit and during their initial or entire period of stay in the new destination. In Kenya, the overarching context of low and non-regular incomes, insecure employment, and insurance schemes that are not adapted to people's needs and preference are identified as key hindrances to health care for individuals in the informal sector, including small-scale farmers and pastoralists, estimated at $74 \%$ of the total workforce in the country (Kenya National
Bureau of Statistics, 2003). Hunt (1989) further noted that migrants are prone to poor working conditions because they are difficult to unionize or to organize for resistance to employer exploitation. Consequently, migrant workers are particularly vulnerable to adverse health risks more so in the prevailing context in which migrants are recruited from rural areas to work in industrial and extractive sectors, with little consideration for their safety or health care (Hunt, 1989).

In Southern Africa the condition of migrants is worsened by the general assumptions that: the regional migrant populations are larger than they actually are; movement of people is associated with poor health hence the notion that foreigners bring diseases; and that present regional migrants are placing an additional burden on the public health systems of destination countries (Veary, 2009). In the case of South Africa, while access to health care is guaranteed by government policy, obtaining documentation needed to access health care remains a big challenge. Irregular migration- which is 
estimated to be prevalent in the region especially in South Africa- presents a peculiar challenge for undocumented migrants who are more likely to be scared of seeking care from the public health care system for fear of being identified and deported (Health and Development Network, 2006). In some cases, language is identified as a barrier to accessing health care services among migrants, together with negative attitudes of health care workers to migrants, which stems from limited knowledge of migrants' right to services.

Other social determinants of migrants' health include poverty, education, employment, micro and macro environmental conditions at different stages of the migration process $(\mathrm{WHO}, 2010)$. Classifying migration as a primary determinant of health, IOM (20I la) particularly identified its influence on several factors that contribute to poor health outcomes among migrants. These factors have been summarized as: (i) individual lifestyle factors (low educational attainment, low socio-economic status, smoking, alcohol and drug abuse, irregular migration status, low health literacy and poor health-seeking behavior); (ii) social and community influences (separation from family, anti-migrant sentiment in the host community and the lack of migrant-inclusive services); (iii) living and working conditions (limited supply of, or access to, clean water and sanitation, unavailability of safe housing, unfavorable work conditions and lack of gainful employment); and (iv) general socio-economic, cultural and environmental conditions (lack of legislation to ensure migrants' access to health and social services, effective policies to protect labor migrants' rights and welfare, and laws penalizing discriminatory practices (IOM, 20IIa).

In terms of particular health challenges, the most recent evidence has identified the prevalence of noncommunicable diseases (NCDs, HIV/AIDS, tuberculosis and waterborne diseases as the commonest health problems among migrants in recent years in the region (IOM, 20llb). The key health vulnerabilities are discussed in detail in the subsequent sections.

\section{Vulnerability to HIVIAIDS}

The origins of HIV/AIDS have been debated widely and it is an issue that has attracted a lot of myths but its epidemiology is strongly associated with migration (Lurie, 2006). While some people have blamed it on the western countries where it was first detected (Stadler, 2003), others have associated it with witchcraft (Stadler, 2003; Orubuloye and Oguntimehin, 1999) and God's punishment for promiscuity (Jackson, 2002), hence the stigma that has been attached to people infected with HIV.
Among the Tonga of Zambia AIDS was strongly believed to come through much travels as business men and women travel to different towns where they mix with many people. It is not clear when HIV/AIDS first emerged but earliest assertions suggest that HIV existed as far back as 1959 (Hopper, 1997; Zhu et al., 1998; Papathanasopoulos et al., 2003; Sharp et al., 200I). However, the earliest case of AIDS was linked to a young Norwegian sailor who was infected with HIV-I group O-probably in Cameroon in 1961-2 (Hooper, 1997). Recent evidence on the spread of HIV/AIDS in East Africa also points to the crucial role of population movements in the spread of HIV-I subtype C, which is the most virulent strain of HIV. According to Delatore (20I2), various clades of HIV-I have been traced to their origins in Burundi around 1962 and with notable expansion in the 1970s in Ethiopia, Kenya, Tanzania and Uganda.

In Southern Africa, Webb (1998) observed the crucial role of the Kariba Nexus in spreading HIV. The Kariba nexus is an area encompassing the Southern Province of Zambia up as far as Lusaka and Mongu in Western Province, western and central Zimbabwe, northern Botswana and the Caprivi Strip of Namibia. This area has one of the highest HIV infection rates in the world. The opening up of the Trans-Caprivi Highway through the construction of the Katima-Mulilo bridge and the intended construction of the Kazungula bridge across the Zambezi River is expected to increase movements of people in this region.

Several other studies have documented the role of rural-urban migration and other types of movement in increasing risky behavior and HIV infection (Lurie, 2006; Mberu \& White, 20II; Oster, 2008; Crush et al., 2005; Voeten et al. (20I0). According to Crush et al. (2005), there is considerable evidence that migration plays a key role in increasing susceptibility to HIV, sexually transmitted infections (STIs) and other opportunistic infections. Migrant men are more likely to have casual partners and to engage with sex workers, many of whom are migrants. There is consensus of evidence in the region that people who migrate in search of work or those who are highly mobile, such as truck drivers, and people living close to trucking routes are at elevated risks of HIV and more likely to be infected with other STIs (Crush et al., 2005). In the same light, Lurie (2006) observed that the probability of having HIV/AIDS in South Africa was high in couples where one of the spouses had spent some time away from home. Female sex workers, some of whom are migrants, are particularly vulnerable to HIV. Transactional sex, or the exchange of money and gifts for sexual activities within non-marital relationships was considered a 
contributing factor to the disproportionate prevalence of HIV/AIDS among young women in urban Kenya (Luke et al., 20I I).In sum, geographical mobility and urbanization have been implicated in problematic sexual behavior, increased levels of debauchery and vulnerabilities, all of which are elevated among certain class of migrants and mobile populations, especially distress migrants, refugees and asylum seekers. A group of studies has emphasized the social disruptions, which characterize migration and the relationships between migration and behavioral change (Alirol et al. 201 I; Stack, 1994; Sampson \& Laub, 1993; Vold \& Bernard, 1986). The particular massive migration of young and unmarried adults from presumably conservative rural environments to more sexually permissive African cities in recent years, has been suggested as partly responsible for the much higher HIV seroprevalence levels observed in urban than rural areas (United Nations, 1994). The dynamics of transmission become more complex as frequent movements between cities, towns and the home villages remain the norm for many migrants in the region (Geschiere \& Gugler, 1998; Gugler, 1991). This pattern of circular migration complicates the direction of the influence of migration on sero-conversion, in both urban and rural areas, since it is also suggested that migrants themselves engage in sexual practices that elevate their risk of acquiring HIV/AIDS (Brockerhoff \& Biddlecom, 1999; Caldwell et al., 1997; Chirwa, 1997; Lurie et al., 1997).

These findings are consistent with why HIV/AIDS intervention programs in countries in the region over a period of twenty years have targeted mobile groups such as truckers (Kilimwiko, 1991; Nyambedha et al., 2003; Ramjee and Gouws, 2002). Contrary to assertions that offering free access to antiretroviral therapy (ART) to migrants in countries like South Africa, will lead to more people migrating in order to access ART and that migrants are less likely to adhere to ART, Veary (2009) observed that regional migrants receiving ART in Johannesburg had fewer hospital admissions, less missed appointments for ART initiation, faster median time to ART initiation, better retention in care and lower mortality. Earlier, the Health and Development Networks (HDN) (2006) noted that the health of migrants in Southern Africa was jeopardized by lack of access to health services such as voluntary counselling, testing and treatment of STIs. In Kenya, inadequate coordination among stakeholders, limited comprehensive interventions targeting female sex workers and their clients and inadequate supplies of commodities have been identified as key challenges in delivering HIV services among mobile populations especially along the main transport corridors (IOM, 20I Id).

\section{Vulnerability to Tuberculosis}

Tuberculosis (TB) cases are on the increase globally with one third of the world's population being estimated to be infected with the disease (Nesher et al., 20l2). Tuberculosis is also one of the main opportunistic infections among HIV-positive patients and is highly associated with HIV/AIDS infection. In some parts of Africa, 30 percent of TB patients have HIV. According to Nesher et al (2012), for each 100,000 people, Swaziland has the greatest number (627) of tuberculosis cases in the world; Zambia is in the third position with (445), fourth is Djibouti (382), seventh is Zimbabwe (29I), and eighth is Kenya (29l). The emergence of drug-resistant strains of TB have accentuated the situation and even though few studies have been conducted on this type of TB in sub-Saharan Africa, there are indications that there is growing concern about it in the region. For example, the recent increase in incidence of TB in Southern Israel has been attributed to the influx of African refugees from the East sub-Saharan desert area (Nesher et al., 20I2). Alirol et al. (20II) also observed that owing to poor human disease surveillance systems in African cities, a number of diseases such as AIDS, tuberculosis and malaria are often undetected until it is too late, making their management problematic. The situation is worse among migrants as physicians in the destination countries may not be familiar with some diseases. In Kenya, a total of 105,78 I cases of TB were diagnosed in 2010 with migrant populations being at risk of developing infection due to reactivation of latent TB or contracting the disease in the country (IOM, $20 \mid$ Ic).

The daily use of public transport was implicated as a risk factor for acquiring TB, with rural-urban migration increasing its spread (IOM, 20l Ib). Urban congestion especially in slums, which are often the major recipients of rural-urban migrants, also increases the spread of TB. In addition overcrowded accommodation where migrants and mobile populations live, for instance refugee camps and crowded informal settlements, increase the transmission of TB. This is compounded by poor health services in these places of residence, inadequate nutrition and poor working conditions such as in mining and other extractive industries. Approximately 70 per cent of urban residents in subSaharan Africa reside in informal settlements and those migrants who 'hide' in such settlements make it more difficult for local authorities to plan for their health and social services (IOM, 20l lb). It has also been noted in relation to Kenya that the challenges faced in the control of TB are compounded by lack of inter-country referral systems owing to insufficient 
collaboration on TB management with neighboring countries.

Imprisonment and detention also pose major health risks for migrants, including exposure to $T B$ and in some cases multi-drug resistant TB (MDR-TB). A formative study of the health vulnerability of migrants in mixed flows from the East and Horn of Africa transiting other countries en-route to South Africa reported cases of MDR-TB in a prison in Zambia. Migrants, mainly men, who are imprisoned in Zambia, are exposed to MDR-TB and when released could spread it thereby posing a major health risk in the region; making migrant men face a higher risk of TB (IOM, 20I3).

It is important to note that a corpus of studies have linked the unprecedented growth of the TB epidemic in Africa to mostly the HIV epidemic (Ansari et al., 2002; Chaisson \& Martinson, 2008). Although HIV is Africa's leading cause of death, TB is the most common coexisting condition in people who die from AIDS: autopsy studies show that 30 to $40 \%$ of HIVinfected adults die from tuberculosis (Ansari et al., 2002). Among HIV-infected children, tuberculosis accounts for up to one in five of all deaths (Chintu et al., 2002). Building on the same premise, The World Health Organization (WHO) attributes the quadrupling of TB in certain African countries to the deadly synergy between TB and HIV and drugresistant strains of TB and their affinity to HIV, underscoring increased risk of exposure in the age of globalization and porous borders (Chaisson and Martinson, 2008). The countries in East and Southern Africa typify geographical proximity as well as cultural and social affinity of people across countries with huge volumes of movement of people and animals across boundaries.

One key challenge regarding the relationship between migration and TB is that migrants are not screened for TB prior to arrival at destinations and during their stay. Consequently, the incidence among migrant/mobile population groups are not documented, despite evidence that the TB burden was increasing as more cases of multi-drug resistant TB were being diagnosed among migrants (IOM, 20IIc).

Contact tracing is also difficult, which coupled with differing drug regimens, lead to high default rates among mobile populations such as pastoralists (IOM, 20IIC). Consequently, documenting the burden of TB due to migration, conducting surveillance programs, public health education, outreach services and dissemination of standard treatment guidelines among key stakeholders, remain a key challenge that calls for intervention, more so in the face of persistent conflicts that generate distress migration across the ESA region.

\section{Vulnerability to Non-Communicable Diseases}

Non-communicable diseases (NCDs) account for over 60 per cent of global mortality burdens, with the particular burdens associated with cardiovascular diseases, diabetes, chronic respiratory diseases and cancers projected to further increase (IOM, 20l Ib). NCDs such as diabetes are also related to other diseases such as AIDS and TB. For Africa, a region reeling from the devastating effects of HIV and several communicable diseases, the emergence of health challenges associated with NCDs exacerbates the already serious situation. In Mozambique for example, NCDs account for 28 per cent of deaths (Goma et al., 20II; Silva-Matos \& Beran, 20I2). A number of factors have been attributed to the rise in cases of NCDs including unhealthy diet, inactivity and other lifestyle factors (WHO, 20I2). In the case of diabetes, which is among the most prevalent NCDs in Africa, urbanization process has been singled out as having a significant impact among urban residents, with prevalence being between I.5 to 4 times higher than among rural residents (WHO, 20I2). Motala \& Ramaiya (20I2) showed that majority $(68 \%)$ of people with diabetes in sub-Saharan Africa live in urban areas, and the number is expected to increase to $78 \%$ by 2030 . Relocation to urban living leads to lifestyle changes: reduced physical activity, reliance on motorized transport and changes in dietary habits, which are notable risk factors for NCDs.

However, only 15 percent of people with diabetes in Africa have been diagnosed (Motala \& Ramaiya, 2012). Even though the $\mathrm{WHO}$ estimates the global burden of diabetes at 3.5 percent among all noncommunicable diseases (NCDs), the Africa region may not adequately cope with the disease burden that will be caused by diabetes if no strategies are put in place before the problem escalates as projections indicate that up to 24 million people in Africa will have diabetes by 2030 (WHO, 2012). Furthermore, unlike other NCDs such as cancer and hypertension, diagnosis of diabetes is not very well integrated with other health services and the number of people with this condition could be much higher than the existing estimates. The situation could be worse among migrants, especially the undocumented ones, as their access to health care is very limited (IOM, 20IIc). Even though no estimates of prevalence are available among migrants, the issue of stress-related problems is seemingly an important factor to consider among migrant/mobile populations. According to Veary \& Nunez (20II), forced migrants are vulnerable to stress, which may lead to mental ill-health and other problems. In the case of South Africa "daily stressors" among forced migrants include problematic access to documentation, basic services, shelter and livelihood opportunities and xenophobia, all of which are 
negatively associated with emotional wellbeing and may exacerbate any pre-existing trauma or emotional distress. Furthermore, the context of urban inequalities in a city like Johannesburg also affects non-migrants and is identified as a major stressor, making neuropsychiatric conditions the third ranked burden of disease in South Africa after HIV/AIDS and other infectious diseases (Veary \& Nunez, 20II). Further, apart from access to health care, undocumented migrants generally tend to live and work under deplorable conditions (IOM, 20I Ic).

In Kenya, cases of mental health are on the increase as well suggesting the need for health care system to address the problem (IOM, 20I Ib). The most affected are the irregular migrants, with fear and anxiety over the unknown, sense of loss or culture of death, stress and post-traumatic stress disorders as well as sexual exploitation of women and girls being identified as the most common psychosocial experiences (IOM, 20I Ib).

\section{Vulnerability to Malaria}

Malaria continues to be a major global public health problem impacting 109 countries globally and is ranked the fifth cause of death worldwide (WHO, 2013). Further, $\mathrm{WHO}$ (2013) estimated 655,000 malaria deaths in 2010, of which 9l per cent were in Africa. Mobile populations face complex obstacles in accessing essential health care, including malaria prevention, screening and treatment, as they enter and leave endemic or non-endemic areas on a daily basis. Some population groups are at considerably higher risk of contracting malaria, and developing severe disease, than others. These include infants, children under five years of age, pregnant women, migrants with HIV/AIDS, as well as non-immune migrants, mobile populations and travelers $(\mathrm{WHO}$, 20I3).

Available evidence suggests that given similar exposure, adult men and women are equally vulnerable to malaria infection, except for pregnant women who are at greater risk of severe malaria in most endemic areas. People who move from dry highlands to wet lowlands can become exposed to malaria. Migrants may be particularly vulnerable to malarial infection because of the fatigue and malnutrition that accompany relocation. The risk is highest when migrants move to tropical areas, which are home to a larger number of infectious disease pathogens than areas at higher altitudes (Population Action International, 20/2).

Sharp increases in malaria morbidity and mortality across all age groups was reported among Ethiopian migrants from low to high transmission areas (Prothero, 200I). Seasonal migration of workers has been associated with malaria epidemics in Kenya
(Bloland \& Williams, 2003). Meade \& Earickson (2000) documented the effect of population movement on the extent of malaria drug resistance as migrants that move from areas where resistance strains of the parasite have been identified introduced the strain into areas where resistance had not been acquired. In Ethiopia, national documents demonstrate that approximately $68 \%$ of the country's population is under the threat of both Plasmodium falciparum and Plasmodium vivax, the major Anopheles arabiensis malaria vector, with significant variability across different transmission strata produced in part by geography and climate and by recent scale up of control measures (Ministry of Health- Ethiopia, 20II). With high levels of outmigration of Ethiopians to countries of East and Southern Africa, as refugees, asylum seekers and economic migrants, there is need for specific focus on screening them for malaria infections. Ethiopian and Somali migrants from low malaria zone migrating to South Africa face high risks of malaria infection during transit as they pass through Malawi and Mozambique, sleeping in the bush for days, while trying to avoid being caught by government officials (IOM, 20I3).

\section{Other Health Vulnerabilities}

Migrants or mobile populations in the East and Southern Africa region also face other forms of health vulnerabilities beyond those already discussed, which include waterborne diseases and maternal and child health morbidities. For waterborne diseases, cholera and schistosomiasis (bilharzia) have been documented as particularly problematic among mobile populations (Gaffga et al., 2007; Alirol et al., 20II). Urbanization poses great challenges on management of solid waste and most urban residents of congested cities in sub-Saharan Africa have no access to safe drinking water and lack adequate sanitation (Alirol et al., 20l I). According to Gaffga et al. (2007), the highest cholera density within Africa is in the ESA region with Mozambique and Somalia having the highest median incidences of cholera. Gaffga et al. (2007) identified social disruption and poverty as the main drivers of the spread and lethality of the cholera epidemic in this region. Accordingly to Gaffga et al. (2007), 28 (56\%) of the 50 nations in sub-Saharan Africa have been at war since 1980 leading to distress migration, disruption of access to clean water, waste disposal, and health care services and consequent lethal cholera epidemics among internally displaced and refugee populations. For example, the large epidemic in Goma in 1994 resulted in an estimated 58,000 to 80,000 cases of cholera within one month and a case fatality rate of at least 6\% (Gaffga et al., 2007). 
Maternal and child health outcomes among migrants are also poorer compared with non-migrant populations. Bocquier et al. (2010) observed that the likelihood of dying among children born of new migrant mothers in slum areas of Nairobi was higher than that of children born to older migrant and nonmigrant mothers within these areas. This points to issues of adaptation as the new migrant mothers may not yet be integrated into the new environment and may not know how and where to seek health care services for their children (Bocquier et al., 2010). In most situations, tumbledown, private-owned and unlicensed clinics might be the only health facilities to which residents of Nairobi's slums have access to. Elsewhere, women in slums have been observed to have lower immunization coverage, contraceptive use and antenatal care than their counterparts in other urban settings (Alirol et al., 20II). In South Africa, a comparative analysis of child survival between South African and Mozambican communities showed a significantly higher risk of child mortality in the latter than the former community, pointing to poor access to health and social services among Mozambican migrants (Khan et al., 2003).

Malnutrition is also a serious health challenge among migrants and particularly refugees in this region leading to other health problems such as anemia. According to the United Nations High Commission for Refugees/World Food Program (UNHCR/WFP, 2006), there were high rates of malnutrition in UNHCR/WFP supported protracted refugee situations worldwide, including Chad (I8\%), Eritrea (18.9\%), Ethiopia (up to 19.6\%), Kenya (20.6\%), Sierra Leone (16.0\%) and Sudan (16.0\%). This raised questions of why the high rates of malnutrition exist despite agency intervention, implementing partner programming and donor assistance. The agencies further noted that of the protracted refugee situations worldwide, camps in Africa were the only ones with malnutrition rates consistently above 15\%, while those in Asia had rates below I 2\% (UNHCR/WFP, 2006).

\section{Discussion and Conclusion}

Our review has demonstrated that migrant/mobile populations face a number of challenges in accessing health care while in transit as well as in their destination countries. Health vulnerabilities are particularly more severe among illegal or undocumented migrants as they are unable to approach public health institutions due to fear that they will be repatriated to their countries of origin. However, in terms of disease epidemiology, vulnerability to diseases faced by migrants/mobile populations also affects host populations especially in urban areas. This problem is compounded by the general lack of cross-country disease screening mechanisms or referral systems for migrants or mobile populations in the East and Southern Africa Region. Given the congestion in cities, the transmission of new strains of communicable diseases such as TB and cholera is faster among urban residents than their rural counterparts. While nonmigrants have better access to health services than migrants in general, the risk of contracting sexually transmitted diseases such as HIV/AIDS is similar among both migrants and non-migrants due to the level of social interaction where they live or work. This highlights the specific need for investments in health infrastructure at the regional level for crosscountry disease screening mechanisms and/or referral systems for migrants or mobile populations in destination countries.

The ESA region also has one of the worst global maternal and child health outcomes but the significance of migration on these indicators is not very clear. There is also a lot of information that has not been documented in a systematic way about the main challenges migrants face in this region. The evidence presented based on available literature may not provide the full picture of the situation in this region as it mostly covers Kenya and South Africa. There is, therefore, need to conduct special studies that will include many countries in the region. The analyses we anticipate should focus on at least one core indicator of the identified diseases or health problems. Despite the lack of documented evidence from all countries in the region, especially among internal migrants and displaced groups, our findings highlight the need for a comprehensive region-wide approach in migration management, especially of interventions addressing health vulnerabilities faced by migrants across origin, transit and destination areas.

Although data are difficult to obtain, available evidence suggests high prevalence of urban refugees, internally displaced persons and asylum seekers (not living in camps) in Kenya. Official estimates put the number of registered urban refugees at 46,000 (UNHCR, 2009b), but according to the Refugees Consortium of Kenya (RCK), this number could be as high as 100,000 in Nairobi alone, most of whom are unregistered (RCK, 2008). This is consistent with data from other regions of Africa such as Cameroon, where the overwhelming majority of refugees $(83 \%$ in 2005) were located in urban areas. This creates particular logistical challenges in terms of administering targeted interventions, in contexts where poor socio-economic situations of countries do not allow urban refugees to become self-reliant and less dependent on humanitarian assistance 
(Mberu and Pongou, 2012). There may therefore be need for national and regional policies and program interventions targeting such vulnerable groups. Beyond urban refugees, other groups in urban areas of the ESA region requiring such interventions include slum residents, street children, the disabled, IDPs, and cross-border migrants. Research efforts aimed at understanding the composition and characteristics of these groups, their particular health vulnerabilities, appropriate intervention models as well as new and innovative approaches geared towards meeting their health needs should be an important part of the process.

\section{Acknowledgments}

Analysis and writing time for this paper was funded by International Organization for Migration with support from Swedish International Development Agency (SIDA), and the general support grants to the African Population and Health Research Center from SIDA (Reference Number 20I I-00I578), the William and Flora Hewlett Foundation (Grant Number 2009$405 \mathrm{I}$ ) and the Rockefeller Foundation (Grant Number 2009SCG302).

\section{References}

Alirol, E., Getza, L., Stoll, B., Chappuis, F., \& Loutan, L. (20II). Review: Urbanisation and infectious diseases in a globalised world. The Lancet, II (February): |3|-|4|.

Adepoju, A. (1977). Migration and development in tropical Africa: some research, priorities. African Affairs, 76(33): 210-225.

African Population and Health Research Center (APHRC). (2014). Population and Health Dynamics in Nairobi Informal Settlements. Nairobi Kenya: African Population and Health Research Center.

African Population and Health Research Center (APHRC). (2002). Population and Health Dynamics in Nairobi Informal Settlements. Nairobi Kenya: African Population and Health Research Center.

Ansari NA, Kombe AH, Kenyon TA, Hone NM, Tappero JW, Nyirenda ST, Binkin NJ, Lucas SB. (2002). Pathology and causes of death in a group of 128 predominantly HIVpositive patients in Botswana, 1997-1998. International Journal of Tuberculosis and Lung Disease, 6 (I): 55-63.

Bloland, P.B., and H.A. Williams (2003). Malaria Control During Mass Population Movements and Rural Disaster. Washington, D.C.: The National Academies Press.

Bocquier, P., Donatien, B., Zulu, E. M., Muindi, K., Konseiga, A., \& Ye, Y.(20I0). Do Migrant Children
Face Greater Health Hazards in Slum Settement? Evidence from Nairobi, Kenya. Journal of Urban Health, 88(Suppl. 2): p. S266-S28I.

Brockerhoff, M., \& Biddlecom, A. (1999). Migration, sexual behavior and risks of HIV in Kenya. International Migration Review, 33(4): 833-856.

Caldwell, J. C., Anarfi, J. K., \& Caldwell, P. (1997). The social context of AIDS in sub-Saharan Africa. Population and Development Review, 15(2): 185234.

Carballo, M. (2005). Migration and maternal and child health: the example of Western Europe. In International Migration and the Millennium Development Goals: Selected Papers of the UNFPA Expert Group Meeting, Marrakech, Morocco, II-I 2 May.

Chaisson, R.E. and Martinson, N.A. (2008) Tuberculosis in Africa - Combating an HIVDriven Crisis. New England Journal of Medicine, 358: 1089-1092.

Chintu C, Mudenda V, Lucas S, et al. (2002). Lung diseases at necropsy in African children dying from respiratory illnesses: a descriptive necropsy study. Lancet, 360: 985-990.

Chirwa, W. C. (1997). Migrant labour, sexual networking and multi-partnered sex in Malawi. Health Transition Review, 7(Supplement 3): 5-I5.

Cohen, B. (2006). Urbanization in developing countries: Current trends, future projections, and key challenges for sustainability. Technology in Society, 28: 63-80.

Crush, J., Williams, V., \& Peberdy, S. (2005). Migration in Southern Africa, 2005, Global Commission on International Migration: Geneva, Switzerland.

Delatorre, E.O.B., (20I2) Phylodynamics of HIV-I Subtype C Epidemic in East Africa. Plos One, 7(7).

French, D. C., \& Dishion, T. J. (2003). Predictors of early initiation of sexual intercourse among highrisk adolescents. The Journal of Early Adolescence, 23(3): 295-3I5.

Gaffga, N.H., Tauxe, R. V., \& Mintz, E. D. (2007). Cholera: A New Homeland in Africa. The American Journal of Tropical Medicine and Hygiene, 77(4): 705-7I 3.

Garenne M. (2006). Migration, urbanization and child health: an African perspective. In: Tienda $M$ et al (eds). Africa on the move: African migration and urbanization in comparative perspective. Johannesburg: Wits University Press.

Geschiere, P., \& Gugler, J. (1998). The urban-rural connections: changing issues of belonging and identification. Africa, 68(3): 309-319.

Goma, F.M., Nzala, H. S., Babaniyi, O., Songolo, P., Zyambo, C., Rudatsikira, E., Siziya, S., \& Muula, A. 
S. (20II). Prevalence of hypertension and its correlates in Lusaka urban district of Zambia: a population based survey. International Archives of Medicine,. 4(34): doi: 10.1186/1755-7682-4-34.

Gugler, J. (1991). Life in a dual system revisited: urban-rural ties in Enugu, Nigeria, 196|-87. World Development, 19(5): 399-409.

Health Development Network (2006). HIV and people on the move: Risk and vulnerabilities of migrants and mobile populations in Southern Africa, Health and Development Networks: Pretoria, South Africa.

Hervitz, H. M. (1985). Selectivity, adaptation or disruption? A comparison of alternative hypotheses on the effects of migration on fertility: the case of Brazil. International Migration Review, 19(2): 293-317.

Hooper, E.,(1997). Sailors and star-bursts, and the arrival of HIV. BMJ, 315: 1689-1691.

Hunt, C.W. (1989). Migrant Labor and Sexually Transmitted Disease: AIDS in Africa. Journal of Health and Social Behaviour, 30(4): 353-373.

IOM (20I3). Health Vulnerabilities Study of Mixed Migration Flows from the East and Horn of Africa and the Great Lakes region to Southern Africa. [online] Available from: http://publications.iom.int/bookstore/free/Migratio n_Health_Study_FINALweb.pdf [Accessed 30 October 2013].

IOM, (20IIa). An analysis of migration in Kenya Healthy migrants in healthy communities

IOM, (20IIb). Migration Health: Report of IOM Activities, 20II.

IOM, (20IIc). Migration Health: Report of IOM Activities 2011, International Organization for Migration: Geneva, Switzerland.

IOM (20IId) Response Analysis: Combination HIV Prevention Programming along the Northern Transport Corridor in Kenya. www.kenya.iom.int/resources/.../352 87ab7 f0e3e02 e36 2c92 44I6347/ Id 8eb.

IOM (2009) Session Summary Report: Sub-plenary 5 - Health Promotion: An Approach to Improving the Health of Migrants, IOM, Nairobi.

Jackson, H. (2002). AIDS Africa: Continent in crisis. Harare: SAfAIDS.

Kaufman, C. E., Clark, S., Manzini, N., \& May, J. (2002). How community structures of time and opportunity shape adolescent sexual behavior in South Africa. Working papers No. I59. New York: The Population Council.

Kenya National Bureau of Statistics (2003). Report of 1998/99 Labour Force Survey. Nairobi, Kenya: Kenya National Bureau of Statistics.

Khan, K., Collinson, M., Tollman, S., Wolff, B., Garenne., \& Clark, S. (2003). Health consequences of migration: Evidence from South Africa's rural northeast (Agincourt), in African Migration in Comparative Perspective: Johannesburg, South Africa.

Kilimwiko, L. (|99|). Condoms hitch lift with truckers. WorldAIDS, I7(9).

Lee, B. S., \& Faber, S. (1984). Fertility adaptation by rural-urban migrants in developing countries: the case of Korea. Population Studies, 38(I): | | I - 156.

Leon D.A. (2008). Cities, Urbanization and Health. International Journal of Epidemiology, 37: 4-8.

Luke, N., Goldberg, R.E., Mberu, B.U., Zulu, E.M. (20II). Social Exchange and Sexual Behavior in Young Women's Premarital Relationships in Kenya. Journal of Marriage and Family, 73 (Oct.): $1048-1064$.

Lurie, N.M. (2006). The epidemiology of migration and HIV/AIDS in South Africa. Journal of Ethnic and Migration Studies, 32 (4): p. 649-666.

Lurie, M.N. (2004). Migration, sexuality and the spread of HIV/AIDS in rural South Africa. In: Migration Policy Series (J. Crush, ed.). Southern African Migration Project and Southern African Research Centre, Cape Town, South Africa.

Lurie, M. N., Harrison, A., Wilkinson, D., \& Karim, S. (1997). Circular migration and sexual networking in Kwazulu/natal: implications for the spread of HIV and other sexually transmitted diseases. Health Transition Review Supplement, 3(7): 1727.

Mazars, C., Matsuyama, R., Rispoli, J., and Veary, J. (20/3). The Well-Being of Economic Migrants in South Africa: Health, Gender and Development. Geneva: International Organization of Migration (IOM).

Mberu, B.U. and Pongou, R. (20/2). Crossing Boundaries: Internal, Regional and International Migration in Cameroon. International Migration, 54(4): (doi: I 0. I I I I/j. I 468-2435.20I2.00766.x).

Mberu, B.U. and White, M.J. (20lI). Internal Migration and Health: Premarital Sexual Initiation in Nigeria. Social Science and Medicine, 72(8): / 284- 2293.

Mberu B.U. (2006). Internal Migration and Household Living Conditions in Ethiopia. Demographic Research, 14(2I): 509-540.

Meade, Melinda S. and Earickson, Robert (2000). Medical Geography. New York, Guilford Press.

Miles, M.B. and Huberman, A.M. (1994). Qualitative Data Analysis: An Expanded Sourcebook. Thousand Oaks, CA: Sage.

Ministry of Health (20II). Malaria Programme Performance Review: Aide Memoire Addis Ababa, Ethiopia: Ministry of Health. 
Motala, A., \& Ramaiya, K. (20|0). Diabetes:the hidden pandemic and its impact on sub-Saharan Africa, Diabetes Leadership Forum: Copenhagen.

Nesher, L., Riesenberg K., Saidel-Odes, L., Schlaeffer, F., \& Smolyakov R. (20I2). Tuberculosis in African Refugees from Eastern Sub-Sahara Region. IMAJ, 14: III-114.

Nyambedha, O.E., Wandibba, S., \& Aagaard-Hansen, J. (2003). Changing patterns of orphan care due to the HIV epidemic in western Kenya. Social Science \& Medicine, 57: 30I-3II.

Orubuloye, I.O., \& Oguntimehin, F. (1999). Death is pre-ordained, it will come when it is due: attitudes of men to death in the presence of AIDS in Nigeria. Resistances to Behavioural Change to Reduce HIV/AIDS Infection in Predominantly Heterosexual Epidemics in Third World Countries, p. I0I-III.

Oster, Emily (2008). Routes of Infection: Exports and HIV Incidence in Sub-Saharan Africa" Mimeo, University of Chicago.

Papathanasopoulos, A.M., M.G. Hunt and T.C. Tiemessen. (2003). Evolution and diversity of HIVI in Africa: A review. Virus Genes, 2003. 26(2): I5I-163.

Population Action International. (2012). Why Population Matters to Infectious Diseases and HIV/AIDS. [Online] Available at: http://populationaction.org/wpcontent/uploads/20I 2/02/PAI 1293-DISEASE_compressed.pdf.

Prothero, R.M. (200I). Migration and malaria risk. Health, Risk \& Society 3(I): 19-38.

Ramjee, G., \& Gouws, E. (2002). Prevalence of HIV among truck drivers visiting sex workers in KwaZulu-Natal, South Africa. Sexually Transmitted Diseases, 29 (I): 44-9.

Refugee Consortium of Kenya (RCK). (2008). Enhancing the Protection of Refugee Women in Nairobi. A Survey on Risks Protection Gaps and Coping Mechanisms of Refugee Women in urban Areas. Nairobi RCK.

Sampson, R., \& Laub, J. (1993). Crime in the making. Cambridge: Harvard University Press.

Sharp, M.P., Bailes, E., Chaudhuri, R. R., Rodenburg, M. C., Santiago, O. M., \& Hahn, H. B. (200I). The origins of acquired immune deficiency syndrome viruses: where and when? Philosophical Transactions of the Royal Society B. 356: 867876.

Silva-Matos, C., \& Beran, D. (20/2). Noncommunicable diseases in Mozambique: risk factors, burden, response and outcomes to date. Globalization and Health. 8(37). doi: |0.1| 86/1744-8603-8-37.
Stack, S. (1994). The effect of geographic mobility on premarital sex. Journal of Marriage and Family, 56(I): 204-208.

Stadler, J. (2003). Rumor, gossip and blame: implications for HIV/AIDS prevention in the South African Low Veld. AIDS Education and Prevention, 15(4): 357-368.

United Nations. (1994). AIDS and the demography of Africa. New York: United Nations, Department for Economic and Social Information and Policy Analysis.

United Nations (20/4). World Urbanization Prospects: The 2014 Revision, Highlights (ST/ESA/SER.A/352). New York: United Nations Department of Economic and Social Affairs, Population Division.

UN-HABITAT (2008). Regional updates: Africa at a glance. State of the world's cities 2008/2009: Harmonious cities. UN-HABITAT.

UN-HABITAT and WHO (20I0). Hidden cities: unmasking and overcoming health inequities in urban settings. World Health Organization, The WHO Centre for Health Development, Kobe, and United Nations Human Settlements Programme.

UNHCR. (2009). Refugees and Asylum Seekers in Kenya. Statistical Summary 3I December 2009.

UNHCR/WFP. (2006). Acute Malnutrition in Protracted Refugee Situations: A Global Strategy. In UNHCR/WFP Global Nutrition Strategy: UNHCR/WFP.

Veary, J. (2009). Migration and Health Delivery Systems in Southern Africa, Open Society Initiative of Southern Africa: South Africa.

Veary, J., Wheeler, B., \& Bleeker-Jurgens, S. (20I0). Migration and health in SADC: A review of literature, IOM Regional Office of Southern Africa: Pretoria, South Africa.

Veary, J., \& Nunez, L. (20II). Towards improving forced migrant access to health and psychosocial rights in urban South Africa-a focus on Johannesburg, ACMS: Migration Issue.

Voeten, H.A.C.M., Vissers, D. C. J., Gregson, S., Zaba, B., White, R. G., de Vlas, S. J., \& Habbema, J. D. (20/0). Strong Association Between InMigration and HIV Prevalence in Urban SubSaharan Africa. Sexually Transmitted Diseases, 37(4): 240-243.

Vold, G., \& Bernard, T. (1986). Theoretical criminology. New York: Oxford University Press.

Webb, D. (1998). The political economy of HIV/AIDS: a case study of the "Kariba nexus" AIDS Analysis Africa 8(2): 7-9.

WHO (20I3) Malaria High Risk Groups. [Online] Available at: http://www.who.int/malaria/areas high_risk_groups/en/[Accessed: I3/I I/20 I3]. 
WHO (2012). Annual Report of the WHO Country Office Zambia 2011, 2012, WHO: Lusaka, Zambia.

WHO (2010) Health of migrants: the way forward report of a global consultation, Madrid, Spain, 3-5 March 2010. http://www.who.int/hac/ events /consultation report health_migrants_colour web.pdf.
Wisner B. and Adams J (Editors). (2002). Environmental Health in Emergencies and Disasters: A Practical Guide. WHO: Geneva.

Zhu, T., Korber, T. B., Nahmias, J. A., Hooper, E., Sharp, M. P., \& Ho, D. D. (1998). An African HIVI sequence from 1959 and implications for the origin of the epidemic. Nature, 39l.

Zulu, E.M., F.N.-A. Dodoo, and A.C. Ezeh. (2002). Sexual risk-taking in the slums of Nairobi, Kenya, 1993-98. Population Studies, 56(3): 3 | 1-323. 